\title{
Significance of Dyspnoea as a Symptom in the Emergency Department of the Primary Healthcare Centre
}

\author{
Žana M Maksimović, ${ }^{1,2}$ Nada Banjac, ${ }^{3,4}$ Miloš Čović ${ }^{3}$
}

\begin{abstract}
Background/Aim: Dyspnoea represents a subjective feeling of laboured breathing of different intensity. The aim of this study was to determine how often patients come with dyspnoea to a local Emergency Department of the Primary Healthcare Centre (EDPHC) and to analyse the assumed aetiology, diagnostics and therapy of the dyspnoeic patients.

Methods: The records of the EDPHC of the City of Banja Luka for the period between 1 October 2019 to 31 December 2019 of all patients older than 15 years of age that have reported laboured breathing were identified and analysed. Following parameters were recorded: age, gender, diagnostics performed, administered therapy, whether the patient was examined in the field or in the ambulance, as well as whether the patient was referred to a hospital (Cardiology, Pulmonology or another department) or not.

Results: Laboured breathing was reported by 665 patients. Out of this number, 108 patients were examined by their family doctor, 407 patients in EDPHC ambulance and 150 patients in the field. The average age of the patient was $61.03 \pm 19.17$, with an equal distribution in males and females. The aetiology of dyspnoea was cardiac and pulmonary in one-third of patients each, whereas the diagnosis in the other patients was versatile, from anxiety disorders, musculoskeletal diseases and active malignancy to unspecified chest pain that could not receive a definitive diagnosis. One half of the patients ( $\mathrm{N}=261$ or $46.86 \%)$ was completely taken care of in the ambulance or in the field, 199 (35.73\%) patients were sent to a cardiologist, 87 (15.62 $\%)$ to a pulmonologist and $10(1.80 \%)$ of patients to another specialist. Referral to hospital was registered more often in men $\left(\chi^{2}=9.195, p=0.027\right)$, elderly $\left(\chi^{2}=53.29\right.$, $\mathrm{p}<0.001)$, people with lower peripheral oxygen saturation $\left(\mathrm{SpO}_{2}\right)\left(\chi^{2}=120.61, \mathrm{p}<\right.$ $0.001)$ and people with significant deviation of normal blood pressure values $\left(\chi^{2}=\right.$ 120.61, $\mathrm{p}<0.001$ ).

Conclusion: Dyspnoea can be caused by an array of different diseases and more than one diagnostic method is necessary to confirm/exclude any of the most common causes of dyspnoea. A broader diagnostical palette in ED would be preferred for purposes of ascertaining a timely diagnosis.
\end{abstract}

Key words: Dyspnoea; Emergency Department; Primary Healthcare Centre; Differential diagnosis.
(1) Primary Healthcare Centre Modriča, Modriča, the Republic of Srpska, Bosnia and Herzegovina;

(2) Centre for Biomedical Research, Faculty of Medicine, University of Banja Luka, Banja Luka, the Republic of Srpska, Bosnia and Herzegovina.

(3) Emergency Department, Primary Healthcare Centre Banja Luka, the Republic of Srpska, Bosnia and Herzegovina.

(4) Department of Emergency Medicine, Faculty of Medicine, University of Banja Luka, Banja Luka, the Republic of Srpska, Bosnia and Herzegovina.

Correspondence:

ŽANA M MAKSIMOVIĆ

M: +387065 970593

E: maksimoviczana85@gmail.com

\section{ARTICLE INFO}

Received: 24 May 2020

Revision received: 7 June 2020 Accepted: 7 June 2020

\section{Introduction}

Dyspnoea represents a subjective feeling of laboured breathing of different intensity. ${ }^{1}$ Patients describe it differently, but the symptoms can be most often divided in three groups: effort (breath-

Copyright $\odot 2020$ Maksimovic et al. This is an open access article distributed under the Creative Commons Attribution License (CC BY), which permits unrestricted use, distribution, and reproduction in any medium, provided the original work is properly cited. This article should be cited as follows: Maksimović ŽM, Banjac N, Čović M. Significance of dyspnoea as a symptom in the emergency department of the primary healthcare centre. Scr Med 2020;51(3):158-65. 
ing requires labour), tightness ("thorax seems too small for comfortable breathing") and air hunger (the patient's feeling that he/she has not inhaled enough air, need for more air)., ${ }^{2,3}$ It is considered that the air hunger originates from stimulating the breathing centre in the brain with hypercapnia and/or hypoxia and labour from muscle afferents and "afferents of breathing".

Dyspnoea is a disabling symptom, trailing by importance only pain and it is estimated that a quarter of the total population in the ambulance complains of breathing discomfort., ${ }^{5}$ It is also an important predictive factor in many diseases, mortality as well as quality of life. Dyspnoea is a better prognostic factor of mortality in patients with chronic obstructive pulmonary disease (COPD) than forced expiratory volume in first second $\left(\mathrm{FEV}_{1}\right)$, and in patients with heart diseases it is better than angina during the stress test. ${ }^{7,8}$

Causes of dyspnoea are many. They are most commonly of pulmonary (pneumothorax, pulmonary embolism, asthma, foreign body in respiratory tract, inhalation of toxic substances, pneumonia, exacerbated COPD, restrictive lung disease, interstitial lung disease, pleural effusion) and of cardiac (myocardial infarction, heart insufficiency, papillary muscle rupture, angina, pericardial effusion, cardiac tamponade) aetiology, but it can be also caused by anxiety disorders, anaemia, bad physical condition, diaphragm paralysis. ${ }^{9}$ Dyspnoea is often the first symptom of some relatively rare diseases. ${ }^{10-15}$

Based on the notion that dyspnoea, as well as pain, are subjective feelings, questionnaires were created as an attempt to define the intensity and type of difficulty that the patients feels, with questionnaires such as Dyspnoea-12, Multidimensional Dyspnoea Profile (MDP), modified Medical Research Council scale (mMRC), Baseline Dyspnoea Index (BDI), Total Dyspnoea Scale for Cancer Patients (TDSC), however each one of them deals with a different disease, so it is impossible to implement any of them as an universal questionnaire of dyspnoea that would help the doctors in the ED. ${ }^{16-19}$ Evaluation of the potential cause of dyspnoea begins initially with anamnesis and physical examination. Alongside, pulse oximetry is very important, then blood pressure values, electrocardiogram (ECG), chest X-ray and eventually, depending on doubt regarding potential causes, also blood gas analysis, complete blood count (CBC) and plasma D-dimer concentrations. ${ }^{20,21}$ With chronic dyspnoea additional examinations might be necessary, such as computerised tomography scan, lung function tests, echocardiography and bronchoscopy.

The goal of this research was to determine how often patients had reported dyspnoea in EDPHC of Banja Luka and to analyse the assumed aetiology, diagnostics and therapy of a dyspnoeic patient. It was also investigated how often a dyspnoeic patient had to be referred to a hospital and based on which parameters.

\section{Methods}

After obtaining the permission of the local Ethics Committee, a retrospective cross-sectional study was conducted. Analysing the protocol of the EDPHC of the City of Banja Luka, between 1 October 2019 and 31 December 2019 data were found for all patients that reported laboured breathing. Only patients older than 15 years of age were recorded, as younger ones were examined by a paediatrician. These patients were further included in analysis, so their age, sex, diagnostics (whether blood pressure was taken and their values, oxygen saturation, ECG, blood tests: CBC, glucose level, D-dimer, troponin), prescribed therapy, whether the examination of the patient was made in the field or in an ambulance, as well as whether the patient was referred to a higher referenced level or not (to cardiology, pulmonology or any other department) were all recorded.

The anonymity of patients was preserved because only the patient's age and sex were recorded, without name or surname, initials or date of birth. Blood pressure values were recorded as: a) normal blood pressure values: 100-140/60-90 $\mathrm{mmHg}$, b) hypotension: $<100 / 60 \mathrm{mmHg}$, c) stage 1 hypertension: $140-160 / 90-100 \mathrm{mmHg}$, d) stage 2 hypertension: $160-180 / 100-110 \mathrm{mmHg}$, e) stage 3 hypertension: $>180 / 110 \mathrm{mmHg}$. If the values of systolic and diastolic blood pressure were found in different categories, the values were classified in the higher category.

Oxygen saturation was analysed by a pulse oximeter. It was analysed whether the abovementioned examination had been performed, as well as whether the values were: a) $\geq 94 \%$, b) $\geq 88$ - $93 \%, c) \geq 80-87 \%, d) \leq 79 \%$. 
D-dimer and troponin were analysed using quantitative turbidimetric immunoassay using a Cobas h-232 device. It was analysed whether the abovementioned examination was performed, as well as whether the values were within the reference values.

The data were processed using IBM SPSS 21.0 software. Categorical data were compared by Chisquare test. After distribution inequality had been determined by Kolmogorov-Smirnov test, continual data were analysed by Mann-Whitney U-test or the Kruskal-Wallis test.

\section{Results}

In the EDPHC of the City of Banja Luka, in the period from 1 October 2019 to 31 December 2019, a total of 8,112 patients were treated. Laboured breathing was found to be a complain in 665 of them, regardless of whether it was the only or just one of the symptoms. Of the given number, 108 patients were examined by their family doctor, while the EDPHC doctors performed supervision and, if necessary, administered therapy while transferring the patients to a hospital. The remaining 557 patients were examined either in the ambulance of the EDPHC (407 patients, or $73.07 \%$ ), or in the field (150 patients, or $26.93 \%$ ).

The distribution of patients is shown in Table 1. It shows equal distribution according to gender. Dyspnoea was more often reported by older patients; half of them were aged over 65 . The average age of patients was to $61.03 \pm 19.17$ years, (95\% CI 59.43-61.62), with median of 65 years and interquartile range of 30 .

Table 1: Gender and age distribution of dyspnoeic patients admitted to the Emergency Department of the Primary Healthcare Centre

\begin{tabular}{|c|c|c|c|c|c|}
\hline \multirow[b]{2}{*}{ Variable } & \multirow[b]{2}{*}{ N (\%) } & \multicolumn{3}{|c|}{ Referred to hospital - N (\%) } & \multirow[b]{2}{*}{ Other } \\
\hline & & No & Cardiology & Pulmonology & \\
\hline \multicolumn{6}{|l|}{ Gender } \\
\hline Male & $281(50.45)$ & $115(40.93)^{*}$ & $114(40.57)^{\star}$ & $48(17.08)^{\star}$ & $4(1.42)$ \\
\hline Female & $276(49.55)$ & $146(52.90)^{*}$ & $85(30.80)^{\star}$ & $39(14.13)^{\star}$ & $6(2.17)$ \\
\hline \multicolumn{6}{|l|}{ Age } \\
\hline $16-30$ & $45(8.08)$ & $38(84.44)^{*}$ & $4(8.89)$ & $3(6.67)$ & $0(0.00)$ \\
\hline $31-64$ & $232(41.65)$ & $126(54.31)^{*}$ & $77(33.19)^{*}$ & $25(10.78)^{*}$ & $4(1.78)$ \\
\hline Over 65 & $280(50.27)$ & $97(34.64)^{*}$ & $118(42.12)^{*}$ & $59(21.07)^{*}$ & $6(2.14)$ \\
\hline Total & $557(100.00)$ & $261(46.86)$ & $119(35.73)$ & $87(15.62)$ & $10(1.80)$ \\
\hline
\end{tabular}

The cause of dyspnoea was of cardiac and pulmonary aetiology in one-third of the patients each, whereas the diagnosis of the other patients was versatile, from anxiety disorders, musculoskeletal disorders and active malignancy to unspecified chest pain that has not received a definitive diagnosis (Table 2).

Table 2: Assumed causes of dyspnoea in patients admitted to the Emergency Department of the Primary Healthcare Centre

\begin{tabular}{|c|c|c|}
\hline Diagnosis & $\mathrm{N}$ & $\%$ \\
\hline \multicolumn{3}{|c|}{ Pulmonary: N (\%) = 193 (34.65) } \\
\hline Pulmonary embolism & 6 & 1.08 \\
\hline Acute respiratory infections & 55 & 9.87 \\
\hline Chronic respiratory infections & 11 & 1.97 \\
\hline Exacerbation of COPD & 62 & 11.13 \\
\hline Exacerbation of asthma & 41 & 7.36 \\
\hline Pleural effusion & 5 & 0.90 \\
\hline Respiratory failure & 13 & 2.33 \\
\hline \multicolumn{3}{|l|}{ Cardiac: $N(\%)=206(36.98)$} \\
\hline Hypertension & 31 & 5.57 \\
\hline Angina pectoris & 86 & 15.44 \\
\hline Acute myocardial infarction & 20 & 3.59 \\
\hline Heart failure & 43 & 7.72 \\
\hline Atrial fibrillation & 3 & 0.54 \\
\hline Pulmonary oedema & 17 & 3.05 \\
\hline Hypotension & 6 & 1.08 \\
\hline \multicolumn{3}{|l|}{ Other: $\mathrm{N}(\%)=158(28.37)$} \\
\hline Anxiety disorders & 39 & 7.00 \\
\hline Myalgia & 15 & 2.69 \\
\hline Unclear aetiology & 17 & 3.05 \\
\hline Active malignancy & 3 & 0.54 \\
\hline Nonspecific chest sensations & 84 & 15.08 \\
\hline Total & 557 & 100 \\
\hline
\end{tabular}

Among the objective parameters, most patients had their peripheral $\mathrm{SpO}_{2}$ measured, blood pressure value, heart rate and ECG taken and, when considered necessary by the doctor, blood analyses - glucose level, complete blood count (CBC), troponin and D-dimer level - determined. Results are shown in Table 3.

Half of the patients had normal values of blood pressure, $7 \%$ of patients were hypotensive and the rest were to some extent hypertensive. Normal $\mathrm{SpO}_{2}$ was present in a bit less than half of the patients, an additional one-third had slightly lower values, where approximately $15 \%$ of the patients had significant hypoxia.

Two-thirds of patients had normal heart rate, $4 \%$ were bradycardic, $10 \%$ had slightly increased heart rate, and $12.57 \%$ of patients had significant tachycardia with or without other heart rhythm disorders. 
Table 3: Values of measured parameters in dyspneic patients admitted to the Emergency Department of the Primary Healthcare Centre

\begin{tabular}{|c|c|c|}
\hline Parameter & $\mathrm{N}$ & $\%$ \\
\hline \multicolumn{3}{|l|}{ TA: N (\%) = 541 (97.13) } \\
\hline Normotensive & 291 & 52.24 \\
\hline Hypertension, stage 1 & 126 & 22.62 \\
\hline Hypertension, stage 2 & 38 & 6.82 \\
\hline Hypertension, stage 3 & 45 & 8.08 \\
\hline Hypotensive & 41 & 7.36 \\
\hline TOTAL & 541 & 97.12 \\
\hline \multicolumn{3}{|c|}{$\mathrm{Sp0}_{2}: \mathrm{N}(\%)=500$ (89.77) } \\
\hline $94 \%$ and more & 246 & 44.17 \\
\hline $88-93 \%$ & 169 & 30.34 \\
\hline $80-87 \%$ & 55 & 9.87 \\
\hline Less than $80 \%$ & 30 & 5.39 \\
\hline TOTAL & 500 & 89.77 \\
\hline \multicolumn{3}{|c|}{ Heart rate: $\mathrm{N}(\%)=516(92.64)$} \\
\hline Bradycardia & 21 & 3.77 \\
\hline $60-100 / \mathrm{min}$ & 370 & 66.43 \\
\hline $101-110 / \mathrm{min}$ & 55 & 9.87 \\
\hline$>110 / \mathrm{min}$ & 70 & 12.57 \\
\hline TOTAL & 516 & 92.64 \\
\hline
\end{tabular}

N: number of patients; \%: percentage of total number of patients; $S p 0$ : peripheral oxygen saturation;

ECG was performed in $77.74 \%$ of patients, which was either normal or led to the establishment of one of the before mentioned working diagnosis. CBC was analysed in 41 patient and blood glucoses level in one-third of the patients. Out of 182 patients, 132 had normal, 2 lower and 48 increased blood glucose values. Troponin was analysed in 64 patients, its values were increased in 10 patients and D-dimer was determined in 23 patients, where almost half of the patients $(10$ patients or $43.48 \%) 10$ patients or $43.48 \%$ had D-dimer values above the upper reference limit.

Administered therapy in dyspnoeic patients is

Table 4: Therapy administered to dyspnoeic patients admitted to the Emergency Department of the Primary Healthcare Centre

\begin{tabular}{|c|c|c|}
\hline Therapy & $\mathrm{N}$ & $\%$ \\
\hline Oxygen & 162 & 29.08 \\
\hline Corticosteroids & 178 & 31.96 \\
\hline Bronchodilatators & 172 & 30.88 \\
\hline Analgesics & 151 & 27.11 \\
\hline Diuretics and/or antihipertensives & 142 & 25.49 \\
\hline Diazepam & 81 & 14.54 \\
\hline Acetylsalicylic acid & 72 & 12.93 \\
\hline Nitrates & 40 & 7.18 \\
\hline Infusion solutions & 31 & 5.57 \\
\hline Beta blockers & 13 & 2.33 \\
\hline Antibiotics & 11 & 1.97 \\
\hline Proton-pump inhibitor & 10 & 1.79 \\
\hline Digoxin & 9 & 1.61 \\
\hline Amiodarone & 9 & 1.61 \\
\hline Cardiopulmonary resuscitation & 2 & 0.36 \\
\hline
\end{tabular}

shown in Table 4. Patients received one or more drugs and two patients (0.36 \%) were in such condition that they required cardiopulmonary resuscitation.

One of the most important parameters observed is the percentage of patients referred to hospital treatment, as well as to which department. Half of the patients ( $\mathrm{N}=261 ; 46.86 \%)$ were completely taken care of in the ambulance/in the field, without need for further diagnostics, 199 (35.73 $\%)$ patients were referred to a cardiologist, 87 (15.62\%) to a pulmonologist, and 10 patients $(1.80 \%)$ to a different specialist (neurologist, infectologist, internist, surgeon) (Figure 1).

It was also analysed whether there was a difference in referring the patients based on specific parameters.

Regarding the gender, men were significantly more often referred to hospital treatment, both to a cardiologist and a pulmonologist (Chi-square test: $\chi^{2}=9.195, \mathrm{df}=3, \mathrm{p}=0.027$ ).

There is also a statistically significant difference

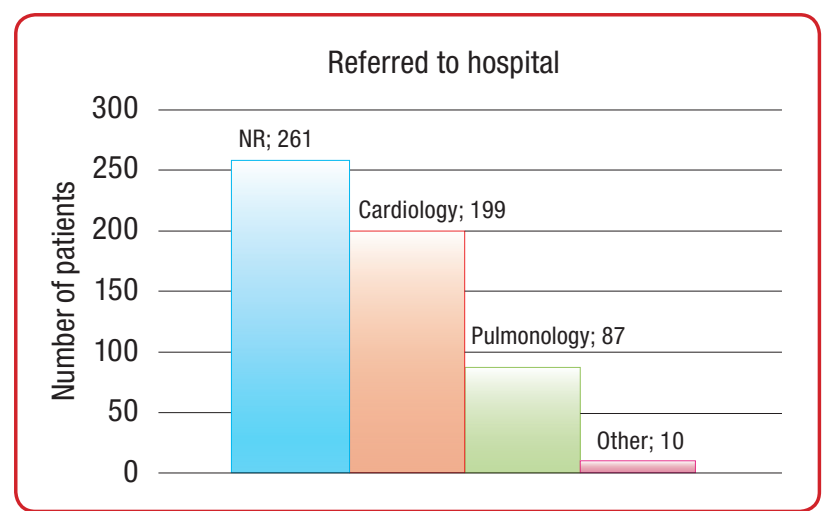

Figure 1. Number of patients treated by the Emergency Department of the Primary Healthcare Centre and referred to a specific department (Cardiology, Pulmonology, Other) or not referred at all (NR)

in the age of the referred patients (Kruskal-Wallis test: $\left.\chi^{2}=53.29, \mathrm{df}=3, \mathrm{p}<0.001\right)$. After a general statistical significance had been shown, differences among the groups were analysed by Mann-Whitney U-test, which showed that older people were significantly more often referred to both a cardiologist (U-test: 16991.00, p < 0.001) and a pulmonologist (U-test: 7085.00, $\mathrm{p}<0.001$ ), but also that there was no statistically significant difference to which department the patient was referred to based on age $(U=8347.00, p=$ 0.63).

$\mathrm{SpO}_{2}$ values greatly influenced the doctor's de- 
cision whether to refer the patient to hospital treatment or not (Chi-square test: $\chi^{2}=120.61$, df $=9, p<0.001)$. Patients with normal blood oxygen saturation were most often not referred for further treatment, whereas those with the lowest values were more often referred to a pulmonologist.

The measured blood pressure values greatly influenced the doctor's decision (Chi-square test: $\left.\chi^{2}=52.81, \mathrm{df}=12, \mathrm{p}<0.001\right)$. Patients with both hypertension and hypotension were most often referred to a cardiologist and normotensive patients either to a pulmonologist or they were not referred for further specialist treatment at all.

Heart rate also significantly influenced the doctor's decision whether to refer the patient to hospital treatment or not (Chi-square test: $\chi^{2}=56.66$, $\mathrm{df}=9, \mathrm{p}<0.001$ ), with the main difference being in bradycardic patients being exclusively referred to a cardiologist, whereas other patients were further referred or not based on other symptoms/indications.

\section{Discussion}

Dyspnoea represents a serious differential diagnostic challenge for a doctor. The challenge is even bigger knowing that the subjective feeling often does not match the objective parameters. ${ }^{22,23}$

Patient distribution by gender was even, which matches the data found in literature. ${ }^{24}$ The interesting finding is that more than half of women were not directed to further treatment (50.29\%), unlike only $40.93 \%$ of men who were. The reason for that can be found in detailed data analysis, where it was found that most common causes of dyspnoea in women were the ones that can be taken care of by the treatment in the EDPHC, like hypertension, exacerbation of COPD and anxiety disorder.

Half of the patients were aged 65 and above and only $8 \%$ of them were under the age of 30 . Age distribution makes sense and it matches the data found in literature, considering that almost all potential dyspnoea causes are more common in the elderly. ${ }^{22}$ The youngest among the examined population were more often hit by unspecific difficulties, myalgia, acute respiratory infections, so only seven of the patients required further examination by a specialist. In the range of 31-65, half of the patients were directed to see a specialist, cardiologist being the most frequent one, three times more often than the others. The reason for that can be found in the fact that at this age, most of the cardiac difficulties appear for the first time. Two-thirds of the patients above the age of 65 are being directed to a hospital treatment, mostly to a cardiologist, unlike middleaged people. The reason for directing elderly to a pulmonologist is that the pulmonary diseases are usually much more often and much more severe in them than in younger people, often with a respiratory insufficiency. ${ }^{25}$ COPD and cardiac disease comorbidity are also common in the elderly, so the doctor has to determine which disease causes the newly created dyspnoea. ${ }^{26}$

How to differentiate the cause of dyspnoea in the ED, with limited diagnostics, is now the question. The doctor's experience is significant, because an experienced doctor can assume the potential cause of dyspnoea and with great probability, just by taking anamnesis and performing physical examination. For that reason, the diagnostic procedures should help the doctor with confirming/excluding the assumed diagnosis. $\mathrm{SpO}_{2}, \mathrm{ECG}$ and blood pressure measurement should be performed in every dyspnoeic patient. The reason why it is not being done in practice is the fact that a certain number of difficulties comes from obvious lighter infections of the upper respiratory tract, such as nasopharyngitis and tonsillitis, where the aforementioned diagnostics are not really necessary. Unfortunately, a certain number of patients simulate their difficulties, making them appear more urgent and serious than they really are.

Almost half of the patients were directed to further treatment and two times more often to a cardiologist than to a pulmonologist, even though the number of cardiologic and pulmonary diagnosis was equal. Reason for that is that most pulmonary diagnosis represent either exacerbation of COPD/ asthma or acute respiratory infection, which can be taken care of and treated in the ED, while the cardiologic diagnosis often require hospitalisation. Data indicate that one-third of dyspnoea causes were of pulmonary aetiology, half of which were exacerbation of COPD/asthma, similar to the literature data. ${ }^{27,28}$ Different studies reported different hospitalisation rates. ${ }^{18,28,29}$ Reason for that can be a different organisation of the healthcare system, primary healthcare and ED availability.

On the other hand, hypertension, rhythm disorder, acute myocardial infarction and unstable angina pectoris are often first time discovered in the ED and therefore require a cardiologist examina- 
tion. ${ }^{30-32}$ Cardiac decompensation and lung oedema and directing them or not often depends on whether the patients appear in the earlier or the later stages of the disease. ${ }^{24,33}$

Certain number of patients has dyspnoeic difficulties because of an earlier diagnosed or undiagnosed psychiatric disorder. ${ }^{34}$ Their differentiation is made even harder by the fact that because of hyperventilation they often have tachycardia and tachypnoea in their report, sometimes even auscultatory wheezing or even hypertension because of the anxiety. Doctors' experience plays a huge part here. On the other hand, patients suffering from COPD and asthma, often remain undiagnosed for the anxiety disorder, which are common cause of disease exacerbations, so the patients show even worse clinical picture and are being treated inadequately. ${ }^{35}$ Depression is also common in patients with cardiac decompensation and is directly related to the dyspnoea frequency. ${ }^{36}$

Values of blood oxygen saturation, blood pressure, frequency, blood glucose, ECG recording, should primarily help the doctor to differentiate the potential cause of dyspnoea, but also their values indicate the severity of the clinical picture. As previously mentioned, it is often the case that the subjective feeling does not match the objective state of the patient, so the objective parameters help the doctor significantly with the diagnostics and the therapy as well. Systematic review article that analysed the dyspnoea in ED showed that there was no single symptom/sign that could exclude heart failure, COPD or pulmonary embolism. ${ }^{37}$

$\mathrm{SpO}_{2}$ values significantly affected the doctors' decision, especially the fact whether the oxygen therapy improved the saturation, so those patients whose saturation stayed low were most often directed to hospital treatment. Those ones with lowest values were usually sent to a pulmonologist.

Heart rate was observed within the whole clinical picture when considering therapy and directing the patient further. Only bradycardia as an individual symptom would affect the decision that such patients were, as a rule, directed to a cardiologist. Tachycardia was obviously regarded as a part of the clinical picture, with increased body temperature, hypertension, arrhythmia, pulmonary embolism, COPD. ECG is also a significant tool that helps the doctor, especially in case of pathological finding and sometimes it gives a reliable diagnosis in cases such as acute myocardial infarction and heart rhythm disorder.
Blood pressure value helped the doctor both with the diagnostics and choice of the therapy, so those patients with higher values were more often referred to a cardiologist. Hypotensive cardiac patients often had a severe clinical picture and their prehospital treatment was limited.

Considering the fact that $\mathrm{D}$-dimer has a negative predictive value, it serves primarily for excluding pulmonary embolism and it is recommended not to be determined as a routine. ${ }^{38}$ On the other hand, troponin values can help the doctor with unspecific changes in the ECG. CBC was determined, weather it was for suspected anaemia or acute respiratory infection.

It is the belief of the authors that the doctors in EDPHC would benefit from additional diagnostics when contemplating the differential diagnosis of dyspnoea, such as X-ray or ultrasonography, wider lab pallet, which at the moment, is not at the doctors' disposal. N-terminal ProBrain Natriuretic Peptide (NT-proBNP) as a reliable parameter of heart failure would be very useful for differentiating dyspnoea in the elderly. Besides, doctors should record the number of respirations per minute in every dyspnoeic patient, considering it was not the case so far. On top of that, it would be preferable to record the body mass index (BMI), considering the correlation found between obesity and dyspnoea. ${ }^{34,39,40}$

\section{Conclusion}

Dyspnoea can be caused by an array of different diseases and more than one diagnostic method is necessary to confirm/exclude any of the most common causes of dyspnoea in the EDPHC.

\section{Acknowledgements}

None.

\section{Conflict of interest}

None. 


\section{References}

1. American Thoracic Society. Dyspnea. Mechanisms, assessment and management: a consensus statement. Am J Respir Crit Care Med 1999 Jan;159(1):321-40.

2. Parshall MB, Schwartzstein RM, Adams L, Banzett RB, Manning HL, Bourbeau J, et al. An official Thoracic Society statement: update on the mechanism, assessment and management of dyspnea. Am J Respir Crit Care Med 2012 Feb 15;185(4):435-52.

3. Banzett RB, Lansing RW, Reid MB, Adams L, Brown R. 'Air hunger' arising from increased PCO2 in mechanically ventilated quadriplegics. Respir Physiol 1989 Apr;76(1):53-67.

4. Lansing RW, Gracely RH, Banzett RB. The multiple dimensions of dyspnea: review and hypotheses. Respir Physiol Neurobiol 2009 May 30;167(1):53-60.

5. Currow DC, Plummer JL, Crockett A, Abernethy AP. A community population survey of prevalence and severity of dyspnea in adults. J Pain Symptom Manage 2009 Oct;38(4):533-45.

6. Grønseth R, Vollmer WM, Hardie JA, Ólafsdóttir IS, Lamprecht B, Buist AS, et al. Predictors of dyspnoea prevalence: results from the BOLD study. Eur Respir J 2014 Jun;43(6):1610-20.

7. Nishimura K, Izumi T, Tsukino $M$, Oga $T$. Dyspnea is a better predictor of 5-year survival than airway obstruction in patients with COPD. Chest 2002 May;121(5):1434-40.

8. Abidov A, Rozanski A, Hachamovitch R, Hayes SW, Aboul-Enein F, Cohen I, et al. Prognostic significance of dyspnea in patients referred for cardiac stress testing. N Engl J Med 2005 Nov 3;353(18):1889-98.

9. Kasper DL, Fauci AS, Hauser SL, Longo DL, Jameson JL, Loscalzo J. Harrison's principles of internal medicine. 19th edition. United States: McGraw-Hill; 2015.

10. Huang L, Touray S, Akalin A, Ahmad S. A 54-Year-Old man presenting with progressive dyspnea and interstitial lung abnormalities. Chest 2019 Mar;155(3):e69e74.

11. Staubach S, Strohm H, Mudra H. Progressive dyspnea and signs of right heart dysfunction. Echocardiography 2017 Jan;34(1):119-21.

12. Moniodis AE, Ginns JN, Systrom DM. Dyspnea and an arteriovenous fistula. Ann Am Thorac Soc 2016 Aug;13(8):1419-23.

13. Agrawal A, Sikachi RR, Koenig S, Khanijo S. A 68-YearOld man with dyspnea on exertion and cough. Chest 2018 Jun;153(6):e139-e145. doi: 10.1016/j. chest.2018.02.030.

14. Türkoğlu Ė, Yavuzgil O. A rare cause of dyspnea: Left atrial angiosarcoma. Anatol J Cardiol 2019 Aug;22(2):96-98.

15. Wang B, Ma D, Qu L, Cao D, Man X. Sinus of Valsalva aneurysm protruding into the mitral anterior leaflet causing dyspnea: A CARE-compliant case report. Medicine (Baltimore) 2019 Nov;98(48):e18169. doi: 10.1097/MD.0000000000018169.

16. Banzett RB, O'Donnell CR, Guilfoyle TE, Parshall MB, Schwartzstein RM, Meek PM, et al. Multidimensional Dyspnoea Profile (MDP): an instrument for laboratory and clinical research. Eur Respir J 2015 Jun;45(6):1681-91.
17. Williams MT, John D, Frith P. Comparison of the Dyspnoea-12 and Multidimensional Dyspnoea Profile in people with COPD. Eur Respir J 2017 Mar 2;49(3). pii: 1600773. doi: 10.1183/13993003.00773-2016.

18. Perez T, Burgel PR, Paillasseur JL, Caillaud D, Deslée G, Chanez P, et al. Modified Medical Research Council scale vs Baseline Dyspnea Index to evaluate dyspnea in chronic obstructive pulmonary disease. Int J Chron Obstruct Pulmon Dis 2015 Aug 18;10:1663-72.

19. Hashimoto $H$, Kanda K. Development and validation of the Total Dyspnea Scale for Cancer Patients. Eur J Oncol Nurs 2019 Aug;41:120-5.

20. Laviolette L, Laveneziana P; ERS Research Seminar Faculty. Dyspnoea: a multidimensional and multidisciplinary approach. Eur Respir J 2014 Jun;43(6):1750-62.

21. Boulding R, Stacey R, Niven R, Fowler SJ. Dysfunctional breathing: a review of the literature and proposal for classification. Eur Respir Rev 2016 Sep;25(141):287-94.

22. Yernault J. Dyspnea in the elderly: a clinical approach to diagnosis. Drugs Aging 2001;18(3):177-87.

23. Thomas P. 'I can't breathe': assessment and emergency management of acute dyspnea. Aust Fam Physician 2005 Jul;34(7):523-9.

24. Obokata M, Olson TP, Reddy YNV, Melenovsky V, Kane GC, Borlaug BA. Haemodynamics, dyspnoea, and pulmonary reserve in heart failure with preserved ejection fraction. Eur Heart J 2018 Aug 7;39(30):2810- 21.

25. Makdee O, Monsomboon A, Surabenjawong U, Praphruetkit N, Chaisirin W, Chakorn T, et al. High-flow nasal cannula versus conventional oxygen therapy in emergency department patients with cardiogenic pulmonary edema: A randomized controlled trial. Ann Emerg Med 2017 Oct;70(4):465-472.e2.

26. Giezeman $M$, Hasselgren $M$, Lisspers $K$, Ställberg B, Montgomery S, Janson C, et al. Influence of comorbid heart disease on dyspnea and health status in patients with COPD - a cohort study. Int J Chron Obstruct Pulmon Dis 2018 Nov 28;13:3857-65.

27. O'Donnell DE, James MD, Milne KM, Neder JA. The pathophysiology of dyspnea and exercise intolerance in chronic obstructive pulmonary disease. Clin Chest Med 2019 Jun;40(2):343-66.

28. Hasegawa K, Sullivan AF, Tovar Hirashima E, Gaeta TJ, Fee C, Turner SJ, et al. A multicenter observational study of US adults with acute asthma: Who are the frequent users of the emergency department? J Allergy Clin Immunol Pract 2014 Nov-Dec;2(6):733-40.

29. Kuan WS, Craig S, Kelly AM, Keijzers G, Klim S, Graham $\mathrm{CA}$, et al. Asthma among adult patients presenting with dyspnea to the emergency department: An observational study. Clin Respir J 2018 Jun;12(6):2117-25.

30. Lippi G, Sanchis-Gomar F, Cervellin G. Chest pain, dyspnea and other symptoms in patients with type 1 and 2 myocardial infarction. A literature review. Int J Cardiol 2016 Jul 15;215:20-22.

31. Koutsampasopoulos K, Grigoriadis S, Vogiatzis I. Exertional dyspnea after myocardial infarction: thinking beyond the diagnosis of heart failure. J Int Med Res 2018 Nov;46(11):4769-4774. doi: 10.1016/j.ijcard.2016.04.045.

32. Bhatia S, Sims JR, Anavekar NS. 75-Year-Old man with chest pain and dyspnea. Mayo Clin Proc 2019 Feb;94(2):341-46. 
33. Kupper N, Bonhof C, Westerhuis B, Widdershoven J, Denollet J. Determinants of dyspnea in chronic heart failure. J Card Fail 2016 Mar;22(3):201-9.

34. Miner B, Tinetti ME, Van Ness PH, Han L, Leo-Summers $\mathrm{L}$, Newman AB, et al. Dyspnea in community-dwelling older persons: a multifactorial geriatric health condition. J Am Geriatr Soc 2016 Oct;64(10):2042-50.

35. Wong MFK, Leung MWM, Leung CM. 'Organic anxiety' in a middle-aged man presenting with dyspnoea: a case report. East Asian Arch Psychiatry 2019 Sep;29(3):978.

36. Fan X, Meng Z. The mutual association between depressive symptoms and dyspnea in Chinese patients with chronic heart failure. Eur J Cardiovasc Nurs 2015 Aug;14(4):310-16.

37. Renier W, Winckelmann KH, Verbakel JY, Aertgeerts B, Buntinx F. Signs and symptoms in adult patients with acute dyspnea: a systematic review and meta-analysis. Eur J Emerg Med 2018 Feb;25(1):3-11.
38. Hadžić R, Maksimović ŽM, Stajić M, Lončar-Stojiljković D. D-dimer: a role in ruling out pulmonary embolism in an emergency care department. Scr Med 2020;51(1):28-33.

39. Ramalho SHR, Santos M, Claggett B, Matsushita K, Kitzman DW, Loehr L, et al. Association of undifferentiated dyspnea in late life with cardiovascular and noncardiovascular dysfunction. A cross-sectional analysis from the ARIC study. JAMA Netw Open 2019 Jun 5;2(6):e195321. doi: 10.1001/jamanetworkopen.2019.5321.

40. 40. Bello NA, Cheng S, Claggett B, Shah AM, Ndumele CE, Roca GQ, et al. Association of weight and body composition on cardiac structure and function in the ARIC Study (Atherosclerosis Risk in Communities). Circ Heart Fail 2016 Aug;9(8). pii: e002978. doi: 10.1161/ CIRCHEARTFAILURE.115.002978 